\title{
"War Epidemiology" Versus "Peace Epidemiology": A Personal View
}

\author{
Mohsen Rezaeian, PhD $^{{ }^{*}}$
}

${ }^{1}$ Epidemiology and Biostatistics Department, Occupational Environmental Research Center, Rafsanjan Medical School, Rafsanjan University of Medical Sciences, Rafsanjan, Iran

\begin{abstract}
Epidemiology can be considered as a responsible public health science the aim of which is to control health problems. One of the most important public health problems is "war". The aim of the present paper, therefore, is threefold: firstly, to determine to what extent war has been investigated from an epidemiological point of view; secondly, what the definition and scope of "war epidemiology" would be; and thirdly, if it would be possible to introduce a new branch of epidemiology entitled "peace epidemiology". In the present study, I have tried to fulfill the aims of the study based on my experiences in war and peace epidemiology and also by reviewing the most relevant websites, documents and papers. Evidence suggests that enough epidemiological studies have not been carried out to determine the sheer public health consequences of war. "War epidemiology" can be defined as "the study of the distribution and determinants of war-related events in specified populations, and the application of this study to the control of war". "Peace epidemiology" is a new branch of epidemiology which "highlights how peace could positively shape our world". Epidemiologists need to produce more scientific evidence about the negative public health consequences of wars and also the positive public health consequences of peace. The ultimate aim of "war epidemiology" is to control war, usually by secondary and tertiary prevention activities. However, the ultimate aim of "peace epidemiology" is to reinforce peace by primary and/or primordial prevention activities.

Keywords: Armed conflicts, Epidemiology, Peace, War-related injuries

Cite this article as: Rezaeian M. "War epidemiology" versus "peace epidemiology": a personal view. Arch Iran Med. 2020;23(4 suppl 1):S38-S42. doi: 10.34172/aim.2020.s8.
\end{abstract}

Received: February 25, 2019, Accepted: October 12, 2019, ePublished: April 1, 2020

\section{Introduction}

Epidemiology can be defined as "the study of the distribution and determinants of health-related states or events in specified populations, and the application of this study to the control of health problems". ${ }^{1}$ Therefore, epidemiology can be considered as a responsible public health science the aim of which is to control health problems. Among the most important public health problems is "war" the extent of which has grown hugely, especially during recent decades. ${ }^{2}$

The aim of the present paper is threefold: firstly, to determine to what extent war as a huge public health problem has been investigated from an epidemiological point of view; secondly, if we categorize epidemiological studies related to war under the umbrella of "war epidemiology", what its definition and scope would be; and thirdly, if it would be possible to introduce a new branch of epidemiology entitled "peace epidemiology".

As a Middle Eastern epidemiologist, I have developed an interest in war and peace epidemiology. ${ }^{3,4}$ Therefore, within the present article, I have tried to fulfill the aims of the study based on my experiences and by reviewing the most relevant websites, documents and papers. It should be noted that in this article, the term "war" includes both "war" which often occurs on a rather large scale between two countries, and also "armed conflict" that usually happens on a rather small scale within one country.

To What Extent Has War Been Investigated from an Epidemiological Point of View?

If we focus only on war-related deaths and not the other public health consequences of war, the World Health Organization (WHO) estimates that in the $17^{\text {th }}$ century, nearly 7 million people lost their lives due to war-related injuries, while in the $20^{\text {th }}$ century, this figure has increased sharply with 191 million people losing their lives. Furthermore, civilian casualties have increased largely from $10 \%$ in the $19^{\text {th }}$ century to $60 \%$ in the $20^{\text {th }}$ century. ${ }^{2}$

These war-related mortality figures clearly highlight that war is a very important public health problem. Therefore, it is essential to determine to what extent war has been discussed within epidemiological fundamental textbooks and articles. I searched one of the excellent textbooks in epidemiology, i.e. "Modern Epidemiology"5 and found out that wars were not mentioned in this textbook at all. I also read a very important article entitled, "Challenges of 
Epidemiology in the $21^{\text {st }}$ Century: Comments from the leaders of several epidemiology associations." ${ }^{\prime 6}$ I noticed that in this article, wars were not mentioned as a challenge. Therefore, the most important question is, "Why are wars not mentioned in such important textbooks and/or articles"?

\section{Why Are Wars not Mentioned in Such Important Textbooks and/or Articles?}

Surely, one can argue several reasons for such a huge negligence. However, in one of my published articles, I have argued that the best answer to this predicament would come from the geographical point of view.? The WHO estimates that only in the year 2000, warrelated injuries have been the $11^{\text {th }}$ leading cause of death in the African Region (AFR) and $18^{\text {th }}$ in the Eastern Mediterranean Region (EMR). Whilst in the same year, war-related injuries were the $34^{\text {th }}$ leading cause of death in the European Region (EUR) and $62^{\text {nd }}$ in the American Region (AMR).

Therefore, based on these figures, in recent years, warrelated deaths should be considered as a very urgent public health problem only in AFR and EMR and not in EUR and AMR. ${ }^{3}$ This might explain why the previously mentioned epidemiological textbook ${ }^{5}$ and article $^{6}$ did not $^{2}$ discuss wars at all since these documents were written by epidemiological colleagues from Western countries, while most public health consequences of war-related problems occur in countries within Africa and the Middle East. ${ }^{3}$

However, for fully comprehending this dilemma, there is one more issue which needs to be addressed, that is, "Which countries invest the most in wars"? To answer this important question, I use with permission two interesting maps from "worldmapper" (https://worldmapper.org/). ${ }^{8}$ In producing these maps, a density equalized cartogram technique has been applied which actually re-sizes each country in proportion to the variable being mapped.

The first map depicts the total military spending (in constant US\$) in 2017 (Figure 1). ${ }^{9}$ As this map shows, the 10 biggest spenders in order of decreasing amount of money spent are the United States, China, Saudi Arabia, India, France, Russia, the United Kingdom, Japan, Germany and South Korea. The size of these countries, especially the United States, has increased hugely. In 2017, the amount of total global military spending has been 1.68 trillion US dollars and the United States alone spent about $35 \%$ of this total value.

The second map depicts the territories resized according to the number of nuclear warheads deployed there in 2017 (Figure 2). ${ }^{10}$ As this map shows, there are four countries that hugely enlarged in size. In 2017, from the total 3760 warheads, 1710 were deployed in Russia, 1650 in the United States, 280 in France and 120 in the United Kingdom. These four countries are among those ten biggest military spenders.

All these have led me to publish an article entitled, "Challenges of Epidemiologists of Developing Countries in the $21^{\text {st }}$ Century". In this article, I have mentioned that wars and armed conflicts are among the most important challenges for the epidemiologists within low- and middleincome countries, especially in the AFR and the EMR. ${ }^{4}$ Taking a closer look at one of these region i.e. EMR reveals startling results.

The EMR is a troubled area in which nearly all countries somehow suffer from wars and their consequences. ${ }^{11}$ During recent years, Afghanistan, Syria, Egypt, Libya, Tunisia, Yemen, Bahrain, Iraq, Palestine, and Somalia have witnessed wars, armed conflicts, turmoil and civil disturbances leading to major waves of migrations. ${ }^{12}$ By the end of 2016, 5.5 million Syrian people and 2.5 million Afghan people are seeking refuge in other countries mainly within the region. ${ }^{13}$ Furthermore, it has been shown that based on the Global Burden of Disease (GBD) 2015 data and compared to similar figures in 1990 , there has been a $+1027 \%$ increase in war deaths in the region. ${ }^{14}$

I also did a piece of research entitled, "Wars versus

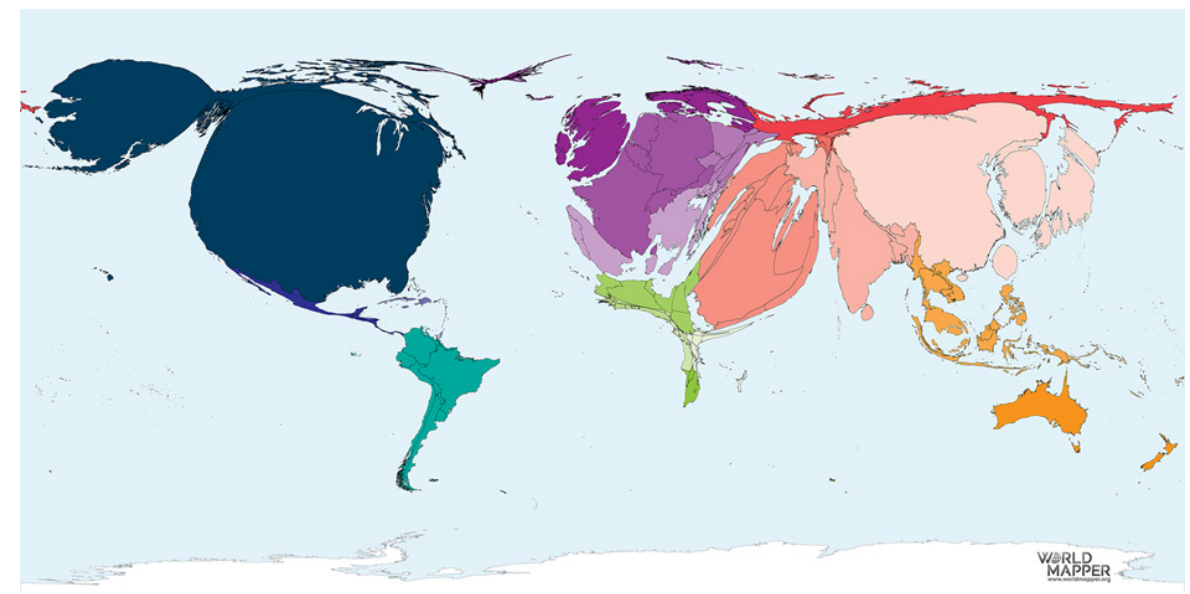




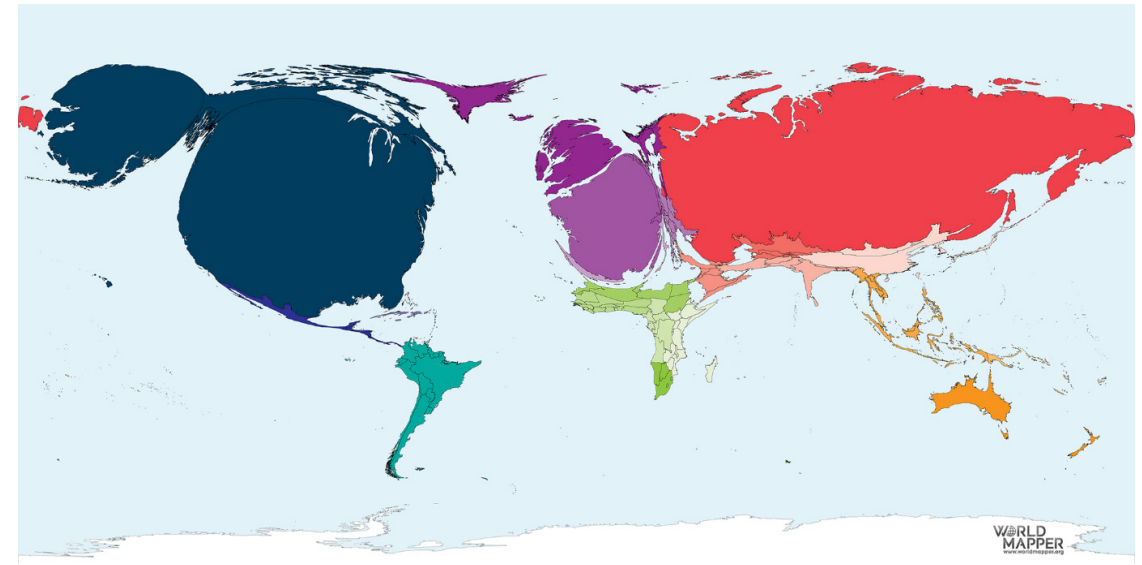

Figure 2. The Number of Nuclear Warheads Deployed in 2017. https://worldmapper.org/maps/nuclear-weapons-strategic-deployed-2017/.

SARS: Are epidemiological studies biased"? In this article, I have considered wars with huge ill-health consequences that have been with human beings from the beginning of the history with 191 million deaths only in the $21^{\text {st }}$ century, and compared the situation with severe acute respiratory syndrome (SARS) as an emerging coronavirus infectious disease, which was internationally recognized in March 2003 with 774 deaths altogether. I did try to highlight how epidemiological studies have responded to these two phenomena by dividing the number of total retrieved epidemiological articles from PubMed by the number of the corresponding deaths. I found out that we have published 1917/774 (nearly 2.5 articles per death) for SARS and 9853/191000 000 (nearly 0.00005 articles per death) for wars. ${ }^{15}$

\section{Why Is Conducting War-Related Epidemiological Studies Necessary?}

As it has been mentioned, the AFR and the EMR have suffered the most from war-related deaths while the EUR and the AMR have invested the most on military expenditures. Furthermore, the insufficiency of epidemiological war studies compared to other public health problems is evident. Therefore, the second most important question is, "Why is conducting war-related epidemiological studies necessary"?

Levy and Sidel have provided seven reasons for the necessity of documenting the adverse effects of wars on population health by conducting epidemiological studies. These reasons include: notifying policy makers and public about the consequences of wars, determining instant needs of affected people, decreasing the possibility of future wars, detecting abuses of international humanitarian law, shielding human rights, stopping the use of indiscriminate armaments such as antipersonnel land mines and biological, nuclear and chemical artilleries, and finally avoiding massacre. ${ }^{16}$

As a result, war-related epidemiological studies could provide valuable evidence for documenting and hopefully reducing the adverse consequence of wars. Therefore, it would be necessary to encourage and promote more war-related epidemiological studies within the affected areas. For this purpose, it would be also possible and necessary to categorize the existing war-related studies under the umbrella of "war epidemiology" to help further development of this branch of epidemiology. In what follows, I will try to provide a firm definition for "war epidemiology" and also to determine the scope of this branch of epidemiology.

\section{What Would Be the Definition and Scope of "War Epidemiology"?}

In my point of view, "war epidemiology" can be defined as, "the study of the distribution and determinants of war-related events in specified populations". In war epidemiology, as we try to quantify all those horrible warrelated events, we have to have a negative look. ${ }^{17}$ Although so far within the present article I have only focused on war-related deaths, it should be borne in mind that there are other negative war-related events, as well.

One may categorize all adverse impacts of wars into the three following areas: firstly, health impacts that include mortality, disability, and morbidity including mental disorders and rape, torture, etc. Secondly, socio-economic impacts including population displacement, collapse of social harmony and cohesion, failure of social services and systems, diverting budget to military expenditures, etc. And thirdly, environmental impacts including air, water, soil and sound pollution plus extra use of fossil fuels. ${ }^{18}$ All these adverse impacts can and should be studied under the umbrella of "war epidemiology".

However, since during war time it would be treacherous and difficult to gather proper epidemiological data, we need to explore appropriate methods of investigations for "war epidemiology". This would help to carry out valid epidemiological studies on the adverse consequences of wars. For example, by applying a cluster sample survey, Roberts and colleagues estimated that nearly 18 months 
after Iraq invasion in 2003, 98000 more deaths occurred mainly due to air strikes by the Coalition forces. ${ }^{19}$ Similarly, by applying another cluster sample survey in Iraq, Burnham and colleagues estimated that as of July 2006, there were 654965 additional post-invasion deaths. ${ }^{20}$

Based on the methods developed and the results of warrelated epidemiological studies, we also need to design and conduct short- and long-term educational programs. These might include workshops, summer schools, master's and even $\mathrm{PhD}$ programs that are conducted through international collaborations. All these efforts would also help to develop educational material including "war epidemiological" textbooks. ${ }^{17}$

\section{Would It Be Possible to Introduce "Peace Epidemiology"?} By focusing on negative war-related events, it seems that the ultimate aim of "war epidemiology" is to control the public health consequence of war usually by accomplishing the secondary and tertiary prevention activities. In other words, in "war epidemiology", the epidemiological studies will be carried out as soon as a war erupts (Figure 3). However, it seems that for primary and primordial prevention of war or even to eradicate this social sickness, we have to obtain a positive look.

This encourages me to publish another article entitled, "Taking the opposite side of issues in epidemiology: 'peace' versus 'war'". In this article I have introduced "peace epidemiology" as a new branch of epidemiology. I have stated that "peace epidemiology... highlights and documents how peace could positively shape our community, our country, our region, and our world". ${ }^{21}$ To put it in another way, in "peace epidemiology", the epidemiological studies should be carried out before a war erupts (Figure 3).

As a result, the ultimate aim of "peace epidemiology" is to reinforce peace by primary and/or primordial prevention of war, or hopefully, even by the eradication of war. It should be noted, however, that there are very few studies which focus on the positive impact of peace on public health. This occurs because peace is a multifaceted

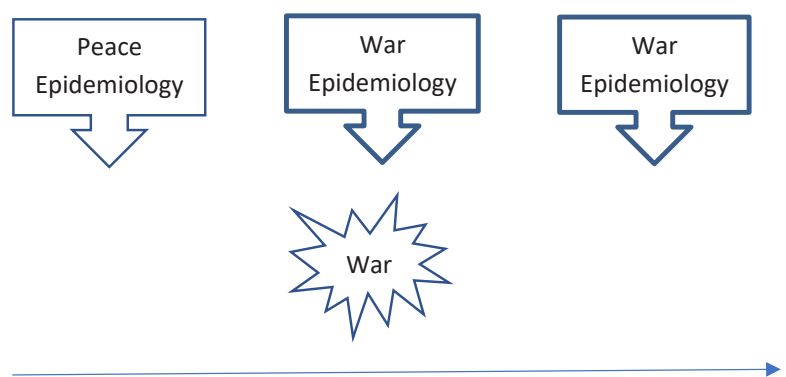

Time

Figure 3. Depicting the Difference Of "War Epidemiology" and "Peace Epidemiology" in Relation to Prevention of War. concept that is more difficult to measure compared with war. $^{22,23}$

Nonetheless, in a recent ecological study by Feyzabadi and colleagues, the association between peace and life expectancy has been examined among world countries from 2007 up to 2012. In this article, the authors applied the Global Peace Index (GPI) which is a score valued between 1 and 5 in which lower score means higher peace. They have shown that empirically, peace has a considerable positive impact on increasing life expectancy even after adjustments have been made for education and economic levels of the countries. ${ }^{24}$

However, in my point of view, the newly developed academic discipline of "Peace through Health $(\mathrm{PtH})$ " has the potential to reinforce peace epidemiological studies. As Arya stated, $\mathrm{PtH}$ tries to highlight how health interventions may contribute to peace in real and probable war regions by developing a framework to conceptualize the role of health workers in peace activities. ${ }^{25}$ As a result, $\mathrm{PtH}$ has been also able to mediate between "war epidemiology" and "peace epidemiology".

The other advantages of $\mathrm{PtH}$ is that this approach has been transformed into the world's first university course. ${ }^{26}$ It has been argued that the academia, especially in the fields of health and medicine, can contribute to peace-building efforts all throughout the world. ${ }^{27,28}$ Therefore, it is hoped that one day, the idea of "peace and war epidemiology" will also transform into a university course.

In conclusions, epidemiologists need to produce more scientific evidence about the negative public health consequences of wars. At the same time, they need to produce even more scientific evidence about the positive public health consequences of peace. The ultimate aim of "war epidemiology" is to control war, usually by secondary and tertiary prevention activities. However, the ultimate aim of "peace epidemiology" is to reinforce peace by primary and/or primordial prevention activities.

\section{Authors' Contribution}

MR is the sole author of the manuscript.

\section{Conflict of Interest Disclosures}

None.

Ethical Statement

Not applicable.

References

1. Porta MS GS, Hernâan M, dos Santos Silva I, Last JM. A Dictionary of Epidemiology. UK: Oxford University Press; 2014.

2. World Report on Violence and Health. Geneva: World Health Organisation; 2002.

3. Rezaeian M. War is an unjustifiable man-made disaster within the Eastern Mediterranean Region. Middle East J Fam Med. 2008;6:14-6.

4. Rezaeian M. Challenges of developing countries' epidemiologists in the 21 st century. Acta Med Iran. 2016;54(1):4-8. 
5. Rothman KJ, Greenland S, Lash TL. Modern Epidemiology. USA: Wolters Kluwer; 2008.

6. Foxman B. Challenges of epidemiology in the 21st century: comments from the leaders of several epidemiology associations. Ann Epidemiol. 2005;15(1):1-4. doi: 10.1016/j. annepidem.2004.09.006

7. Rezaeian M. Illustrating wars and armed conflicts from a different perspective: Who suffers and who invests the most? Middle East J Business. 2011;6(1):12e4.

8. World mapper 2018. Available from: https://worldmapper.org.

9. Military Spending 2017. Available from: https://worldmapper. org/maps/military-spending-2017/?sf_action=get_data\&sf_ data=results\&_sft_product_cat=war-and-peace. Accessed 13 December 2018.

10. Nuclear Weapons 2017. Available from: https://worldmapper. org/maps/nuclear-weapons-2017/?sf_action=get_data\&sf_ data=results\&_sft_product_cat=war-and-peace. Accessed 13 December 2018.

11. Rezaeian M. Age and sex suicide rates in the Eastern Mediterranean Region based on global burden of disease estimates for 2000. East Mediterr Health J. 2007;13(4):953-60.

12. Mokdad AH, Forouzanfar MH, Daoud F, El Bcheraoui C, Moradi-Lakeh M, Khalil I, et al. Health in times of uncertainty in the eastern Mediterranean region, 1990-2013: a systematic analysis for the Global Burden of Disease Study 2013. Lancet Glob Health. 2016;4(10):e704-13. doi: 10.1016/S2214109X(16)30168-1.

13. Mokdad $\mathrm{AH}$. The burden of mental disorders in the Eastern Mediterranean region, 1990-2015: findings from the global burden of disease 2015 study. Int J Public Health. 2018;63(suppl 1):25-37. doi: 10.1007/s00038-017-1006-1.

14. United Nations High Commissioner for Refugees (UNHCR) Global Trends: Forced Displacement in 2016. UNHCR; 2017.

15. Rezaeian M. Wars versus SARS: Are epidemiological studies biased? Eur J Epidemiol. 2014;29(6):453-4. doi: 10.1007/ s10654-014-9919-y.

16. Levy BS, Sidel VW. Documenting the Effects of Armed Conflict on Population Health. Annu Rev Public Health. 2016;37:205-
18. doi: 10.1146/annurev-publhealth-032315-021913.

17. Rezaeian M. War epidemiology: an urgent plea. Epidemiology. 2015;26(1):e10-1. doi:10.1097/EDE.0000000000000209.

18. Rezaeian M. A review on the most important consequences of wars and armed conflicts. Middle East J Bus. 2009;4:7-9.

19. Roberts L, Lafta R, Garfield R, Khudhairi J, Burnham G. Mortality before and after the 2003 invasion of Iraq: cluster sample survey. Lancet. 2004;364(9448):1857-64. doi: 10.1016/S0140-6736(04)17441-2

20. Burnham G, Lafta R, Doocy S, Roberts L. Mortality after the 2003 invasion of Iraq: a cross-sectional cluster sample survey. Lancet. 2006;368(9545):1421-8.

21. Rezaeian M. Letter to the Editor: "Taking the opposite side of issues in epidemiology: 'peace' versus 'war'". Ann Epidemiol. 2014;24(10):791. doi: 10.1016/j.annepidem.2014.07.015.

22. Royce A. A definition of peace. Peace Confl. 2004;10(2):10116.

23. Jose-Miguel FD, Alejandra H-d-M, Isabel J-d-L. Culture of peace: An alternative definition and its measurement. Peace Confl. 2004;10(2):117-24.

24. Feyzabadi VY, Haghdoost A, Mehrolhassani MH, Aminian Z. The association between peace and life expectancy: An empirical study of the world countries. Iran J Public Health. 2015;44(3):341-51.

25. Arya N. Peace through health I: development and use of a working model. Med Confl Surviv. 2004;20(3):242-57. doi: 10.1080/1362369042000248839

26. Arya N. Peace through health II: a framework for medical student education. Med Confl Surviv. 2004;20(3):258-62. doi: 10.1080/1362369042000248848

27. Levy BS, Sidel VW. How academic medicine can contribute to peace-building efforts worldwide. Acad Med. 2009;84(11):1487. doi: 10.1097/ACM.0b013e3181baa209.

28. Khan AM, Janneck LM, Bhatt J, Panjabi R, Marjoua Y, Bharwani A. Building a health-peace movement: academic medicine's role in generating solutions to global problems. Acad Med. 2009;84(11):1486. doi: 10.1097/ACM.0b013e3181bab2bf. 